\author{
Asian Journal of \\ Medical and Biological Research \\ ISSN 2411-4472 (Print) 2412-5571 (Online) \\ www.ebupress.com/journal/ajmbr
}

\title{
Article \\ Study on clinical diseases and disorders of cattle and goat at Gopalgonj District in Bangladesh
}

\author{
Nidra Boti Khan, Dipa Rani Pal and Mohammad Lalmoddin Mollah* \\ Department of Medicine, Surgery and Obstetrics, Faculty of Animal Science and Veterinary Medicine, \\ Patuakhali Science and Technology University, Barisal-8210, Bangladesh \\ *Corresponding author: Dr. Mohammad Lalmoddin Mollah, Department of Medicine, Surgery and Obstetrics, \\ Faculty of Animal Science and Veterinary Medicine, Patuakhali Science and Technology University, Barisal- \\ 8210, Bangladesh. Tel.: +88 04327-73047; Fax: +88 044427-56112; E-mail: belalcnu6@yahoo.com
}

Received: 26 November 2017/Accepted: 14 December 2017/ Published: 28 December 2017

\begin{abstract}
This clinical study was undertaken at the sadar Upazilla Livestock Office, Gopalgonj, Bangladesh to determine the general clinical prevalence of clinical diseases and disorders in cattle and goats during the study period from September to December 2016. Total animals were 105, among them cattle were 60 and goats were 45. Diagnosis was performed on the basis of general examination, physical examination and clinical examination. Clinical examinations were detected 60 (48.38\% of total animals) different types of diseases and disorders in cattle. Whereas fever 3, anorexia 5, bloat 2, dysentery 3 , diarrhoea 4 , fascioliasis 2 , myiasis 5 , FMD 2, papillomatosis 2, ephemeral fever 3, pneumonia 5, mastitis 4, black quarter 1 were recorded. Age wise occurrence in young and adult cattle were $35(58.33 \%) \& 25(41.66 \%)$ respectively. In goat 45 (36.29\% of total animal) different types of diseases and disorders were found. Whereas fever 4 , anorexia 4 , bloat 1 , dysentery 2 , diarrhoea 3 , corneal opacity 2 , mange 3 , myiasis 4 , PPR 10 , pneumonia 8 , tetanus 1 , mastitis 3 were recorded. Age wise occurrence in young and adult goat were $20(44.44 \%)$ and $15(33.33 \%)$ respectively. Diseases and disorders of cattle and goats which were recorded more or less present in both young and adult animals but some of the specific diseases and disorders were in animals due to age susceptibility such as black quarter in young cattle and PPR in goat. From this study it can be said that proper vaccination, treatment and management should be given to minimize the diseases and disorders of cattle and goat.
\end{abstract}

Keywords: cattle; goats; diseases; disorders

\section{Introduction}

Livestock is an important component of the mixed farming system practiced in Bangladesh. The animals kept especially on a farm for economic benefits. Livestock constitute an important part of the wealth of a country, since in addition to draft power and leather; it provides manure, meat and milk to the vast majority of the people. Livestock resources necessarily encompass animal health care and welfare, quality production factors, and effective rearing to keep pace with expansion of entrepreneurship related to concerned industries. It plays an important role in the agricultural production sphere. Statistics show that about $2.9 \%$ of national GDP is covered by the livestock sector, and its annual rate of growth is $5.5 \%$. About $20 \%$ of the population of Bangladesh earns their livelihood through work associated with raising cattle and poultry. Draught power for tilling the land, the use of cow dung as manure and fuel, and animal power for transportation make up a significant portion of the GDP.

In addition, hides and skins, bones, offal, feathers, etc, help in earning foreign exchange. Livestock population in Bangladesh is currently estimated to comprise 25.7 million cattle, 0.83 million buffaloes, 14.8 million goats, 1.9 million sheep, 118.7 million chicken and 34.1 million ducks. The density of livestock population per acre of cultivable land is 7.37 . This density has been increasing every year in the country. The country has a relative 
density of livestock population well above the averages for many other countries of the world. In spite of a high density of livestock population, the country suffers from an acute shortage of livestock products like milk, meat and eggs. The shortage accounts for $85.9 \%, 88.1 \%$ and $70.7 \%$ for milk, meat and eggs, respectively. The annual growth rates of these products have significantly increased in recent years. However, if we desire to meat is increasing demand from domestic production, we will require an increase in production at the rate of 6 to 9 percent per year up to 2021.

Ruminant, especially cattle and goats constitute the major portion of the livestock. Most of these animals are reared under smallholder traditional management system in rural areas. The management practices of animals and geo-climatic condition of Bangladesh are favorable for the occurrence of various diseases. There are about 22.53 million cattle and 14.69 million goats in our country (DLS, 2008-2009). Veterinary hospital is an ideal and reliable source of information about animal diseases and their solution. People from the neighboring areas bring their sick animals to the Veterinary hospital every day. Analysis of the case record gives a comprehensive idea about the disease problems at local areas. Although some reports on clinical case records from Bangladesh Agricultural University Veterinary Clinic (Samad et al., 2002), Ulipur Upazila Veterinary Hospital, Kurigram (Kabir et al., 2010), Chandanaish Upazila of Chittagong district, Bangladesh (Pallab et al., 2012) and Patuakhali Science and Technology University Veterinary Clinic (Rahman et al., 2012) are available but similar report on ruminants are very limited in Gopalganj district of Bangladesh. In the last few decades, as the major infectious diseases of cattle in Bangladesh are brought under control by vaccination and farmer's awareness, emphasis has increasingly shifted to economically important diseases to the dairy producers. However, more information is required to describe the pattern of occurrence of clinical diseases for the provision of appropriate veterinary care and effective disease control programmed and animal production.

A disease is a particular abnormal condition that affects part or all of an organism not caused by external force and that consists of a disorder of a structure or function, usually serving as an evolutionary disadvantage. Disease is often construed as a medical condition associated with specific symptoms and signs. In medicine, a disorder is a functional abnormality or disturbance.

Gopalganj district is one of the important sites for livestock population especially Sadar Upazilla and the most of the common diseases are frequently found in this area. Upazilla Livestock Office is an ideal and reliable source of information about animal diseases and their solution. People from neighboring areas bring their sick animals to the veterinary hospital every day. Analysis of the case record gives a comprehensive idea about the disease problems at local areas. This study was undertaken at the Upazilla Livestock Office. This study was done at this hospital during the period from September to December 2016. The study was conducted with the following objectives:

a) To find out the clinical prevalence of diseases and disorders in cattle and goats at the Upazilla Livestock Office, Gopalganj.

b) To detect the occurrence of diseases and disorders on different age.

\section{Materials and Methods}

\subsection{Study period}

This clinical study was conducted at sadar Upazilla Livestock Office at Gopalgonj district in Bangladesh. To determine the general clinical prevalence of clinical diseases and disorders in cattle and goats during the study period from September to December 2016. All diseased cattle and goat were brought for treatment to the Veterinary Hospital and the entry of them in the registered book.

\subsection{Physical examination}

Physical condition, behavior, posture, gait, superficial skin wound, prolapsed of the uterus and vagina, salivation, nasal discharge, distension of the abdomen, locomotive disturbance etc, were observed by visual examination of the patient. Examination of different parts and system of the body of each of the sick animals were examined by using procedure of palpation, percussion, auscultation, needle puncture and walking of the animals.

\subsection{Clinical examination}

The clinical examinations of animals (cattle $=60$, goat $=45$ ) of different ages were conducted. Temperature, pulse, and respiratory rate from each of these sick animals were recorded. According the merit of the individual case, general clinical examination were conducted on the basis of disease history, owners complaint, symptoms and techniques such as microscopic examination, common laboratory techniques. 


\section{4. Statistical analysis}

The recorded data were compiled and tabulated for statistical analysis. All data were expressed as the mean \pm SD. Evaluation of statistical significance was determined by paired and unpaired Student's t-test. $\mathrm{p}<0.05$ was considered significant.

\section{Results and Discussion}

\section{1. Diseases and disorders of cattle and goat}

The diseases and disorders of cattle and goat as shown in Figure 1. On the 60 recorded clinical cases of sick cattle, bacterial disease was $37.14 \%$, viral disease was $22.85 \%$, parasitic disease was $8.75 \%$, systemic and other disorders was $31.43 \%$. On the 45 clinically sick goats, bacterial disease was $26.65 \%$, viral disease was $22.22 \%$, parasitic disease was $15.54 \%$, systemic and other disorders was $22.22 \%$. This results supports the earlier report of Karim et al., (2014) who recorded 39.94\% bacterial disease, $23.15 \%$ viral disease, $7.75 \%$ parasitic disease, $29.16 \%$ systemic and other disorders in cattle; $29.88 \%$. bacterial disease, $23.74 \%$ viral disease, $16.92 \%$ parasitic disease, 29.46\% systemic and other disorders in goat. Samad (2001), also recorded $42.54 \%$ bacterial disease, $29.15 \%$ viral disease, $5.75 \%$ parasitic disease, $22.56 \%$ systemic and other disorders in cattle. Bangladesh Agricultural University (BAU) Veterinary Clinics, Mymensingh reported that during 1999 to 2001, 25.69\% bacterial disease, $27.52 \%$ viral disease, $20.51 \%$ parasitic disease, $26.28 \%$ systemic and other disorders in goat. The findings of the present study are in agreement with our results. Sarker et al. (2013) conducted a study where $73.95 \%$ and $17.16 \%$ diseases/disorders were recorded in cows and calves respectively. About $58.42 \%, 23.56 \%$ $12.48 \%$ cases were general and systemic, infectious, production diseases/disorders respectively.

\section{2. Systemic disorders of fever, anorexia, bloat, dysentry, diarrhea and corneal opacity in cattle and goat Fever}

The systemic disorders in cattle and goat as shown in Figure 2. Analysis of the clinical cases of ruminants revealed that $5 \%$ cattle and $4.44 \%$ goats were affected with fever of unknown etiology. Samad and Rahman (Samad et al., 2002; Rahman et al., 2012) reported that the of 5.1\% to $12.1 \%$ occurrence of fever in this study supports the earlier reports of cases of fever in cattle and $10.37 \%$ and $4.4 \%$ fever cases in goats (Rahman et al., 2012).

Anorexia: Anorexia was reported in $8.33 \%$ cattle and $4.44 \%$ in goats. Prasad et al. (1980) recorded anorexia syndrome as one of the commonest problem amongst the nonspecific clinical entities in routine ruminant practice.

Bloat: This study were recorded $3.33 \%$ cases of bloat in cattle and $2.22 \%$ in goats. Rahman et al., 2012 reported that the occurrence of bloat in cattle $2.2 \%$ and $2.5 \%$ in goats. Samad (2001) reported $1.83 \%$ prevalence of bloat in cattle and $3.98 \%$ in goats. Sutradhar et al. (2000) reported $1.73 \%$ cases of bloat in cattle. These observations could be compared well with the findings of Hossain et al. (1994) who reported $4.0 \%$ and $0.37 \%$ prevalence of bloat in buffaloes and cattle, respectively. Bloat is mainly a dietary in origin and occurs most frequently in ruminants in Bangladesh.

Dysentry and Diarrhoea: Dysentry cases were 5\% in cattle and 4.44\% in goats. Samad (2001) reported that the $1.76 \%$ and $1.87 \%$ dysentery in cattle and goats respectively. Diarrhoea was found to be the major digestive disorders in ruminants. Diarrhoea cases were $6.66 \%$ in cattle and $6.66 \%$ in goats. These observations could be compared well with the $6.94 \%$ of non-specific diarrhoea in dairy cows, $8.99 \%$ in cow-calves and $12.23 \%$ in goats (Hoque and Samad, 1996, 1997) and $7.6 \%$ in cattle and 12.1\% in goats (Rahman et al., 2012). Samad (2001) reported $25.97 \%$ and $9.91 \%$ of diarrhoeal diseases in cattle and goats, respectively.

Corneal opacity: Corneal opacity in goats was recorded $4.44 \%$ under this group. Rahman et al. (2012) reported $1.9 \%$ and $9.9 \%$ cases of corneal opacity in cattle and goats, respectively.

\subsection{Parasitic diseases of mange, fascioliasis and myiasis in cattle and goat}

The parasitic diseases of cattle and goat as shown in Figure 3. The prevalence of different parasitic diseases were $6.66 \%$ mange, $3.33 \%$ Fascioliasis, $8.33 \%$ myiasis in cattle and $8.88 \%$ myiasis in goat. Howlader et al. (1990) reported $21 \%$ sub clinical prevalence of Fascioliasis in cattle which is higher than clinical occurrence $(5.71 \%)$ recorded in cattle during the study because marshy grazing land and snails are not available in my study area. The clinical prevalence of paramphistomiasis recorded in cattle has been reported from Bangladesh but detail studies on this disease have not yet been made from the country. Mange was recorded 6.66\% in goats. Cases of mange in goats were comparatively higher than the reports of Samad (2001) who recorded $2.11 \%$ mange in goats. Myiasis was recorded in $8.33 \%$ cattle and $8.88 \%$ goats. This observation does not supports the 
report of Rahman et al. (2012) who reported $24.7 \%$ cattle and $16.4 \%$ goats affected with myiasis. In this result may be seasonal variation and not the same time recorded data were collected.

\subsection{Viral diseases food-and-mouth, ephimeral fever, PPR and papillomatosis in cattle and goat}

FMD: The viral diseases in cattle and goat as shown in Figure 4. This study recorded 3.33\% cases of FMD in cattle. Cases of FMD in cattle were comparatively higher than the reports of Samad (2001) and Rahman et al. (2012), $1.79 \%$ and $1.3 \%$ cases of FMD in cattle and only one $(0.08 \%)$ case in goat. Comparatively higher prevalence rates of FMD in cattle have been reported by Sarker et al. (1999) who reported 8.58\% and 5.78\%, respectively.

Bovine epimeral fever: This study recorded 5\% of cases of bovine ephemeral fever in cattle. This finding support the finding of Ali et al. (2011) reported 3.7\% cases of ephemeral fever in cattle.

Papillomatosis: This study recorded $3.33 \%$ cases of papillomatosis in cattle. This findings does not support the reports of Nooruddin and Dey (1990), Samad (2001) and Rahman et al. (2012) reported 0.7\%, 0.58\% and 0.19\% prevalence of warts in cattle from Bangladesh, respectively.

PPR: This study recorded $22.22 \%$ cases of PPR in goats. This finding is higher than the finding of Rahman $e t$ al. (2012) who reported 5.2\% PPR cases in goats. In our study was conducted in winter season, that time is PPR virus prevalence in increased and Rahman et al., (2012) may be seasonal variation, so result is variation.

\subsection{Bacterial diseases}

Tetanus: The bacterial diseases in cattle and goat as shown in Figure 5. This study recorded $2.22 \%$ cases of tetanus in goats. This finding does not support the finding of Samad (2001) and Rahman et al. (2012) reported $1.1 \%$ and $5.2 \%$ tetanus cases in goats.

Black Quarter: Black quarter (BQ) was diagnosed on the presence of pronounced swelling of the affected muscles of upper limb with gaseous crepitation. BQ was recorded in $1.66 \%$ in cattle. These observations does not support the earlier findings of Rahman et al. (2010) and Samad (2008) who reported $0.31 \%, 0.46 \%$ and $0.23 \%$ incidence of BQ in cattle. However, Hoque and Samad (1996) reported 2.17\% incidence of BQ in cattle from different geographical location in Bangladesh.

Mastitis: Mastitis 6.66\% and 6.66\% was diagnosed in cows and does. The findings support the report of Sarker et al. (2013), Samad (2000) and Rahman et al. (2012) who reported clinical mastitis in 5.89\%, 8.71\% and 3.9\% cows, respectively. Nooruddin et al. (1986) and Rahman et al. (2010) also reported $0.37 \%$ and $0.65 \%$ clinical mastitis in goat which is lower than the study.

Pneumonia: Pneumonia recorded in cattle and goats were $8.33 \%$ and $17.77 \%$, respectively. Rahman et al. (2012) recorded $5.1 \%$ and $16.8 \%$ cases of pneumonia in cattle and goats. Cases of pneumonia in cattle were comparatively lower than the earlier reports of Samad (2001) and Samad et al. (2002) who reported 0.84\% and $1.24 \%$ pneumonia in cattle, respectively findings. Ali et al. (2011) conducted a study where worm infestation (51.5\%), pneumonia and pneumonitis $(7.9 \%)$, ephemeral fever $(3.7 \%)$, enteritis $(3.4 \%)$, mastitis (3.2\%), mange (3.2\%), indigestion (2.8\%), were recorded. Rest of the diseases had lower percentage than $2 \%$. Prevalence of diseases was high (42.3\%) in rainy season (June-October) followed by (32.5\%) in winter (November-February) and lowest (25.2\%) in summer season (March-May). Kabir et al. (2010) conducted an investigation where fever (11.30\%), PPR (28.69\%), digestive disorders $(8.69 \%)$, respiratory disorders (6.965), corneal opacity (7.84\%), fascioliasis (10.44\%), skin disease (9.56\%), subcutaneous cyst (2.61\%), and anorexia (6.09\%) were recorded. Age wise prevalence in young and adult goat were $(31.30 \%)$ and $(68.7 \%)$ respectively.

\subsection{Diseases and disorders on the basis of age in cattle and goat}

The diseases and disorders of cattle on the basis of age as shown in Figure 6 . In young $(<1.5$ year) cattle total 35 and in adult ( $>1.5$ year) 25 cases were recorded, on the other hand, in young ( $<6$ month) 20 and in adult $(>6$ month) 15 of goat cases were observed during the study period. In between 35 young cattle, 7 (20\%) cases were bacterial, $2(5.71 \%)$ cases were viral, $4(11.42 \%)$ cases were parasitic, and $9(52.94 \%)$ cases were found as disorders. In between 25 adult cattle, $3(12 \%)$ cases were bacterial, $5(20 \%)$ cases were viral, $3(12 \%)$ cases were parasitic, and $8(47.05 \%)$ cases were found as disorders. In between 20 young goats, $8(40 \%)$ cases were bacterial, $3(15 \%)$ cases were viral, $4(20 \%)$ cases were parasitic, and $4(20 \%)$ cases were found as disorders. In between 15 adult goats, $4(26.66 \%)$ cases were bacterial, 7 (46.66\%) cases were viral, $3(20 \%)$ cases were parasitic, and $8(53.33 \%)$ cases were found as disorders. 


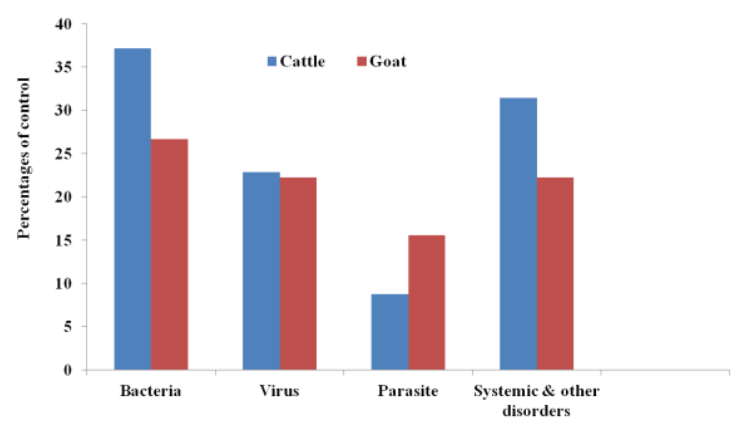

Figure 1. The diseases and disorders of cattle. The clinically sick cattle and goat by bacteria, virus, parasite and systemic \& other disorders. Data are expressed as mean of percentages.

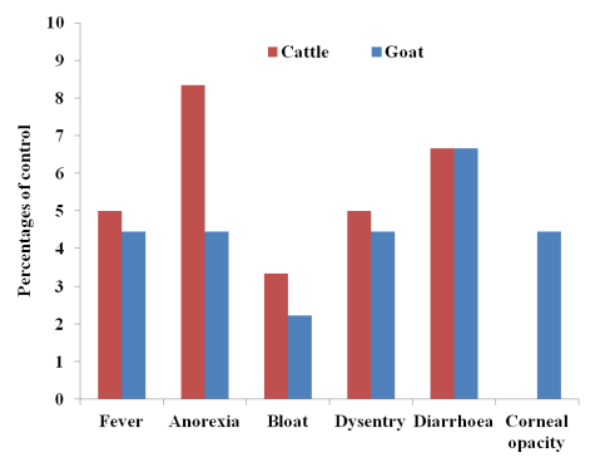

Figure 2. Systemic disorders and other diseases in cattle and goat. The clinically management of fever, anorexia, bloat, dysentry, diarrhoea and corneal opacity. Data are expressed as mean of percentages.

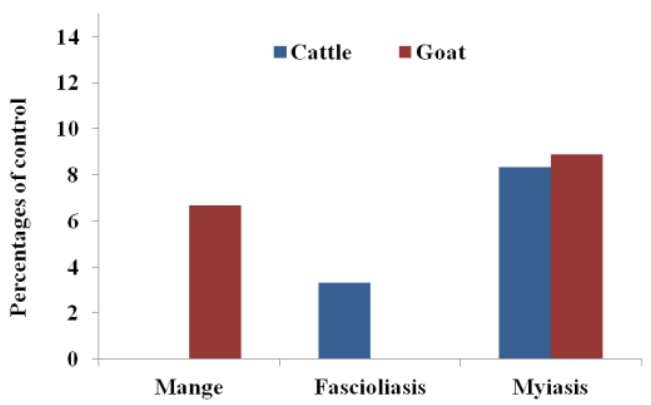

Figure 3. The parasitic diseases of cattle and goat. The clinically management of mange, fascioliasis and myiasis. Data are expressed as mean of percentages.

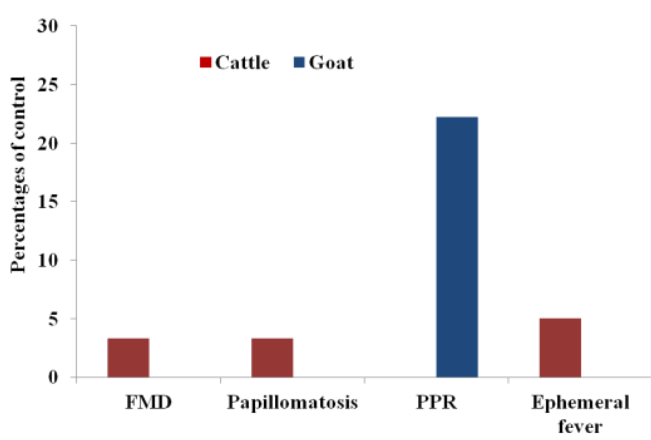

Figure 4. The viral diseases in cattle and goat. The clinically management of food-and-mouth disease, papillomatosis, PPR and bovine ephimeral fever. Data are expressed as mean of percentages. 


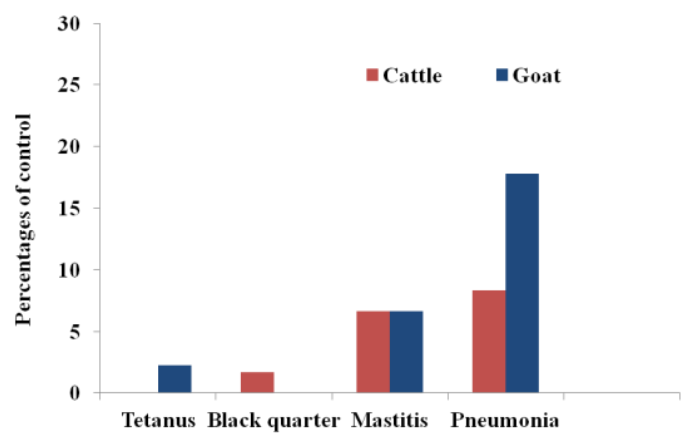

Figure 5. The bacterial diseases in cattle and goat. The clinically management of tetanus, black quarter, mastitis and pneumonia. Data are expressed as mean of percentages.

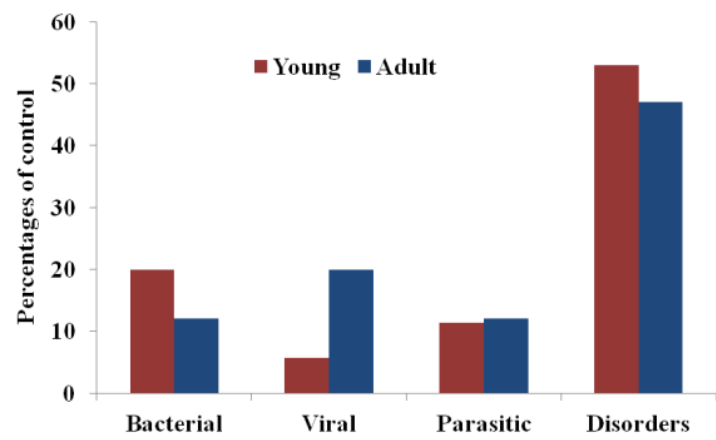

Figure 6. The diseases and disorders of cattle on the basis of age. The clinically management of bacteria, virus, parasite and disorders. Data are expressed as mean of percentages.

\section{Conclusions}

This study was conducted to detect the present situation of clinical diseases and disorders at the sadar Upazilla Livestock Office, Gopalganj. From the study, it was observed that both cattle and goats were most susceptible to bacterial infection. Cattle are less susceptible (16.65\%) to bacterial diseases then goat $(26.65 \%)$. So, regular vaccination and treatment should be given to control the bacteria diseases. The viral diseases like FMD (3.33\%) and PPR $(22.22 \%)$ were frequently outbreaks in cattle and goat respectively. This may be due to these two diseases are contagious, my study period was during the Eid-ul-adha, then these two diseases may be spread from the cattle market and goat market during Eid. So, restriction of movement and frontier vaccination is necessary to control these types of diseases. Parasitic diseases like myiasis (8.33\% in cattle; $8.88 \%$ in goat), fascioliosis (3.33\% in cattle) were found. So, regular dewarming and treatment should be given to control the parasitic diseases. Diarrhoea was recorded $(6.66 \%)$ in cattle and $(6.66 \%)$ in goats. Duration this study period is not sufficient to conduct such type of diseases and the equipments and opportunities in the Upazilla Livestock Hospital are not enough to complete the study accurately. So, further research should be required to determine the accurate prevalence of disease and disorders in cattle and goat. Proper planning and program should be undertaken to prevent and control diseases and disorders of cattle and goat in the study area.

\section{Conflict of interest}

None to declare

\section{References}

Ali MH, MKJ Bhuiyan and MM Alam, 2011. Retrospective epidemiologic study of diseases in ruminants in khagrachari hill tract district of Bangladesh. 9: 145-153.

DLS, 2008-09. Annual Report of Directorate of Livestock Services, Bangladesh.

Hossain MI, AKMM Huq and AKMF Huque, 1994. Pathological investigation on buffalo diseases in Bangladesh. III. Survey of buffalo diseases. Bangl. Vet. J., 11: 123-127.

Hoque MS and MA Samad, 1996. Prevalence of clinical diseases in dairy cross-bred cows and calves in the urban areas in Dhaka. Bangl. Vet. J., 30: 118-129.

Hoque MS and MA Samad, 1997. Present status of clinical diseases of goats in the urban areas in Dhaka. 
Bangl. Vet. J., 31: 35-40.

Howlade MMR, SMZH Chowdhury, MJFA Taimur and S Johan, 1990. Fluke infestations of cattle in some selected villages of Bangladesh . Bangl. Vet. J., 7:45-47.

Kabir MH, MA Reza, KMA Razi, MM Parvez, MAS Bag and SU Mahfuz, 2010. A report on clinical prevalence of diseases and disorders in cattle and goat at the Upazilla Veterinary Hospital, Ulipur, Kurigram. Int. J. of Biol. Res., 2: 17-23.

Karim MR, MS Parvin, MZ Hossain, MT Islam and HT Hussan 2014. A report on clinical prevalence of diseases and disorders in cattle and goats at the upazilla veterinary hospital, Mohammadpur, Magura. Bangl. J. Vet. Med., 12: 47-53.

Nooruddin M and AS Dey, 1990. Further study on the prevalence of skin diseases in domestic ruminants of Bangladesh. Bangl. Vet. J., 7: 75-81.

Pallab MS, SM Ullah, MM Uddin and OF Miazi, 2012. A cross sectional study of several diseases in cattle at Chandanaish Upazilla of Chittagong district. Sci. J. Vet. Ad., 1: 28-32.

Prasad J, SV Uoshi and A Rekib, 1980. Studies on the clinico-pathics of grazing animals in tropics-corneal opacity syndrome. Ind. J. Vet., 57: 310-315.

Rahaman MS, MA Afroz, U Roy and FY Bari, 2010. Analysis of clinical case records from some villages around Bangladesh Agricultural University (BAU) Veterinary Clinic. Int. J. BioRes., 2: 17-20.

Rahman MA, MA Islam, MA Rahman, AK Talukder, MS Parvin and MT Islam, 2012. Clinical diseases of ruminants recorded at the Patuakhali Science and Technology University Veterinary Clinic. Bangl. J. Vet. Med., 10: 63-73.

Samad MA, 2000. Veterinary Practitionar's Guide.1 st pub., LEP pub. No. 07. BAU Campus, Mymensingh.

Samad M A, 2001. Poshu Palon O Chikitshavidda. 2 nd edn. LEP. Pub. No. 7, BAU Campus, Mymensingh

Samad MA, MA Islam and A Hossain, 2002. Patterns of occurrence of calf diseases in the district of Mymensingh in Bangladesh. Bangl. Vet. J., 36: 01-05.

Samad MA, 2008. Animal Husbandry and Veterinary Science.1 st pub., LEP pub No. 11.BAU Campus, Mymensingh.

Sarkar MAS, M Aktaruzzaman, AKMA Rahman and MS Rahman, 2013. Retrospective study of clinical diseases and disorders of cattle in sirajgonj district in Bangladesh. Bangl. J. Vet. Med., 11: 137-144.

Sutradhar BC, MA Hossain and MR Alam, 2000. Incidence of bloat and its response to certain drugs in cattle. Bangl. Vet. J., 17: 37-41. 